\title{
Thomas W. Dunfee Tribute Issue: Introduction
}

\author{
Thomas S. Robertson
}

Over the past several decades, business ethics has emerged as a vibrant domain of academic inquiry, thanks in no small part to Thomas W. Dunfee, a pioneer in the field, who passed away in 2008. This special issue of the Journal of Business Ethics is being published in his memory.

Dunfee held the Joseph Kolodny Chair of Social Responsibility and was the Director of the Zicklin Center for Business Ethics Research at the Wharton School, where he taught for 34 years. A prolific and influential scholar, he published some 50 refereed articles and was the author or editor of more than a dozen books on social contract-based approaches to business ethics, international business ethics, and the social responsibility of business. Over the course of his career, he served as president of both the Academy of Legal Studies in Business and the Society for Business Ethics and was a member of six major editorial boards, including this journal's.

Among Dunfee's many contributions, his most innovative and most enduring was undoubtedly Integrative Social Contracts Theory (ISCT), with Wharton colleague Thomas Donaldson, which continues to inspire important research and debate in the field.

As a legal scholar Dunfee brought an appreciation of human social contracts to decision-oriented business research, arguing that community standards represent a legitimate, real-world source of moral guidance. He merged this idea with Donaldson's classic social contract approach to produce ISCT, which the pair introduced in two articles in 1994 and 1995 and elaborated further in their celebrated 1999 book, Ties That Bind: A Social Contracts Approach to Business Ethics. A theory of impressive analytical rigor, ISCT is at once normative and descriptive, and is as responsive to socio-cultural realities as it is to the imperative of economic efficiency. At its core it is a pragmatic theory, with direct applications for business practice. By requiring managers to consider local community norms, universal moral principles, and the hypernorms that emerge at the nexus of the two, ISCT seeks to guide and enhance ethical decision making throughout the business profession. It is, as Dunfee and Donaldson strove to make it, a theory of social responsibility, and a mandate toward social good.

Over the years, the business ethics community has investigated ISCT's contributions thoroughly. Dunfee and Donaldson have been cited widely by their colleagues, and this journal and others have published numerous articles responding directly to its vision. Ties That Bind, considered by many to be the business ethics' bible, addresses many early critiques of ISCT, further refining the theory and extending its contextual reach.

Rarely are theories so inherently flexible. However, ISCT is hardly a passing fad. Rather, it is a living foundation, firm enough to serve as bedrock for future research, but fluid enough to accommodate an evolving discipline.

Given ISCT's influence, in fact, it is no surprise that the last article Dunfee published in the Journal of Business Ethics was a 10-year retrospective of the theory in 2006, entitled "A Critical Perspective of Integrative Social Contracts Theory: Recurring Criticisms and Next Generation Research Topics." Though proud of his theoretical work, Dunfee never stopped looking forward to its next application. To him, ethics was more than an academic discipline; it was a source of humane action and a real tool for improving people's lives.

In his scholarship, Thomas W. Dunfee reminded us that business can and should be a force for good in 
the world. It is up to his colleagues now to answer that charge. May this volume - which captures the major thesis of Dunfee's prolific career - serve as a tribute to his legacy and a worthy extension of his research and ideas.
Wharton School, University of Pennsylvania, Philadelphia, PA, U.S.A. E-mail: Robertson@wharton.upenn.edu 